\title{
Interstitial lung disease in lysosomal storage disorders
}

\author{
Raphaël Borie $\mathbb{1}^{1,2}$, Bruno Crestani ${ }^{1,2}$, Alice Guyard ${ }^{3}$ and Olivier Lidove $e^{4,5}$ \\ Number 7 in the Series "Rare genetic interstitial lung diseases" \\ Edited by Bruno Crestani and Raphaël Borie
}

\begin{abstract}
${ }^{1}$ Service de Pneumologie A, Centre de Référence des maladies pulmonaires rares, DHU APOLLO, APHP, Hôpital Bichat, Paris, France. ${ }^{2}$ Université de Paris, INSERM U1152, Labex INFLAMEX, Paris, France. ${ }^{3}$ Laboratoire d'anatomopathologie, Hôpital Bichat, Paris, France. ${ }^{4}$ Service de Médecine Interne, Groupe Hospitalier Diaconesses Croix Saint-Simon, Paris, France. ${ }^{5}$ Centre de Référence Maladies Lysosomales (CRML, site Diaconesses Croix Saint-Simon) - Filière Maladies Rares G2M, Paris, France.
\end{abstract}

Corresponding author: Raphaël Borie (raphael.borie@aphp.fr)

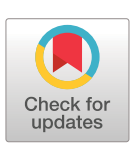

Copyright @The authors 2021
This version is distributed under
the terms of the Creative
Commons Attribution
Non-Commercial Licence 4.0.
For commercial reproduction
rights and permissions contact
permissions@ersnet.org
Received: 16 Nov 2020
Accepted: 27 Dec 2020

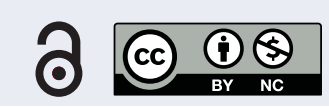

Shareable abstract (@ERSpublications)

Interstitial lung disease is frequent in ASMD and enzyme replacement therapy has shown promising results. https://bit.ly/2XoPR4e

Cite this article as: Borie R, Crestani B, Guyard A, et al. Interstitial lung disease in lysosomal storage disorders. Eur Respir Rev 2021; 30: 200363 [DOI: 10.1183/16000617.0363-2020].

\section{Abstract}

Lysosomes are intracellular organelles that are responsible for degrading and recycling macromolecules. Lysosomal storage diseases (LSDs) are a group of inherited diseases caused by mutations affecting genes that encode the function of the lysosomal enzymes. Three LSDs are associated with lung involvement and/ or interstitial lung disease (ILD): Gaucher disease (GD); Niemann-Pick disease, also known as acid sphingomyelinase deficiency (ASMD); and Fabry disease (FD). In GD and in ASMD, analysis of bronchoalveolar lavage fluid and lung biopsy can be informative, showing foamy cells. In GD, ILD is rare. Enzyme replacement therapy (ERT) has been available since 1991 and has greatly changed the natural history of GD, with pulmonary failure and death reported before the ERT era. In ASMD, ILD is frequent and is usually associated with spleen enlargement, low platelet cell count and low level of high-density lipoprotein-cholesterol. Results of ERT are promising regarding preliminary results of olipudase alfa in paediatric and adult ASMD populations. The most frequent respiratory manifestation in FD is COPD-like symptoms regardless of smoking habit and dyspnoea due to congestive heart failure. Early diagnosis of these three LSDs is crucial to prevent irreversible organ damage. Early initiation of ERT can, at least in part, prevent organ failure.

\section{Introduction}

Lysosomes are intracellular organelles that are responsible for degrading and recycling macromolecules. Lysosomal storage diseases (LSDs) are a group of heterogeneous inherited diseases caused by mutations affecting genes that encode for the function of lysosomal enzymes required for degradation of a wide range of complex macromolecules but sometimes the function of specific transporters needed to export degraded molecules from lysosomes. The resulting lysosomal dysfunction leads to cellular dysfunction and clinical abnormalities [1] (figure 1).

Three LSDs have been associated with interstitial lung disease (ILD) and will be discussed: Gaucher disease (GD), Niemann-Pick disease (acid sphingomyelinase deficiency (ASMD)) and Fabry disease (FD). Hermansky-Pudlak syndrome, another inherited form of ILD, may also be considered a lysosomal disease and was recently reviewed [2]. We do not review Pompe disease, associated with muscle weakness, or other LSDs such as mucopolysaccharidosis and mucolipidosis, which despite their respiratory involvement do not cause ILDs [3-5]. We searched PubMed, PubMed Central, Google Scholar and Embase on 1 October 2020 with the terms: 1) [lung] AND [Gaucher disease]; 2) [lung] AND [Niemann-Pick disease], or [Acid Sphingomyelinase Deficiency]; and 3) [lung] AND [Fabry disease], without limitations on the 


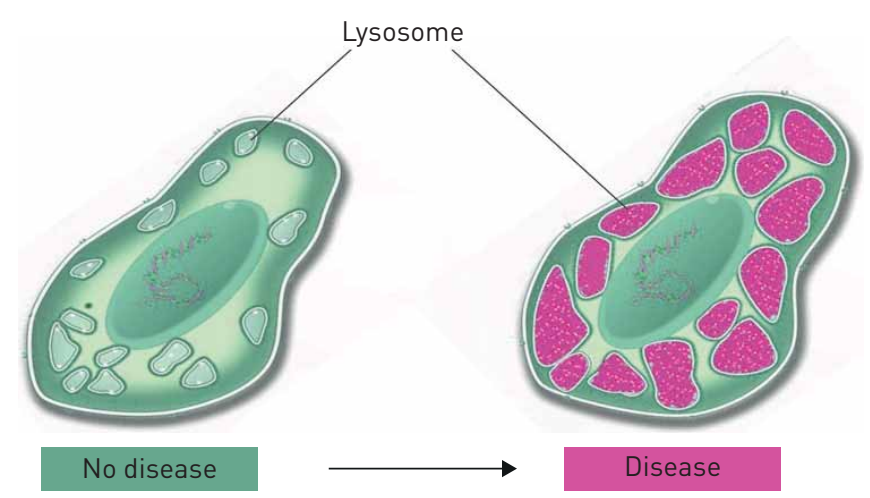

FIGURE 1 Lysosomal storage disorders induce intracellular accumulation of lipids.

age of the patients. We limited our research to articles in English; we did not exclude case reports. We read all titles and abstracts and retrieved all articles of interest to be included in the review.

\section{Gaucher disease}

GD is an autosomal recessive disease secondary to mutations in the glucocerebrosidase gene resulting in deficiency of lysosomal hydrolase acid $\beta$-glucosidase and accumulation of its substrate, glucosylceramide [6] (figure 2). GD is the most prevalent inherited LSD [7]. GD is more frequent in Ashkenazi Jewish populations (up to 1 in 500 people affected) and the world GD prevalence is about 1 in 50000-60000 [7].

Classification of GD includes three major clinical types according to the presence (type 2 and 3) or absence (type 1) of central nervous system involvement.

GD type 1, the most frequent form (90-95\%), is characterised by clinical or radiographic evidence of bone disease (osteopenia, focal lytic or sclerotic lesions and osteonecrosis), hepatosplenomegaly, thrombocytopenia and anaemia, lung disease and absence of primary central nervous system disease [8] (figure 3).

GD types 2 and 3 are characterised by the presence of primary neurological disease and are distinguished by age of onset. GD2 is classified as disease with onset before the age of 2 years, associated with limited psychomotor development and a rapidly progressive course eventually leading to death before age 4. GD3 is disease with onset before age 2 and a more slowly progressive course, with survival into the third or fourth decade [6].

\section{Extrapulmonary disease}

Mean onset of GD1 is around age 20 years, although disease is diagnosed before age 10 in two-thirds of patients and before age 6 in almost half [9]. Most patients (90\%) feature splenomegaly. Mean spleen volume is $1500-3000 \mathrm{~cm}^{3}$ as compared with $50-200 \mathrm{~cm}^{3}$ in the average adult and results in hypersplenism and pancytopenia. Spleen infarction causes acute abdominal pain. Rare splenic rupture may justify surgery [10]. Liver enlargement is common (60-80\%), although cirrhosis and hepatic failure are rare [10, 11]. Up to $40 \%$ of patients with GD1 present a focal lesion in the liver and/or spleen called "gaucheroma" (figure 3). However, patients with GD1 may also present hepatocellular carcinoma or lymphoma with a difficult differential diagnosis.

Cytopenia is almost universal in untreated GD [12]. Thrombocytopenia is the most prominent. Anaemia or leukopenia may be present simultaneously or independently and is related to spleen status. Thrombocytopenia (60-90\% of cases) may result from hypersplenism and/or marrow infiltration. Immune thrombocytopenia has also been reported and should be looked for in case of persistent thrombocytopenia despite ERT. Thrombocytopenia is associated with increased risk of bleeding, particularly in patients with associated coagulation abnormalities. Anaemia (20-50\% of cases) may result from hypersplenism and/or marrow infiltration by Gaucher cells, but iron or vitamin $\mathrm{B}_{12}$ deficiency may contribute to anaemia [12]. Leukopenia is rarely severe. Patients with GD may present low-grade disseminated intravascular 


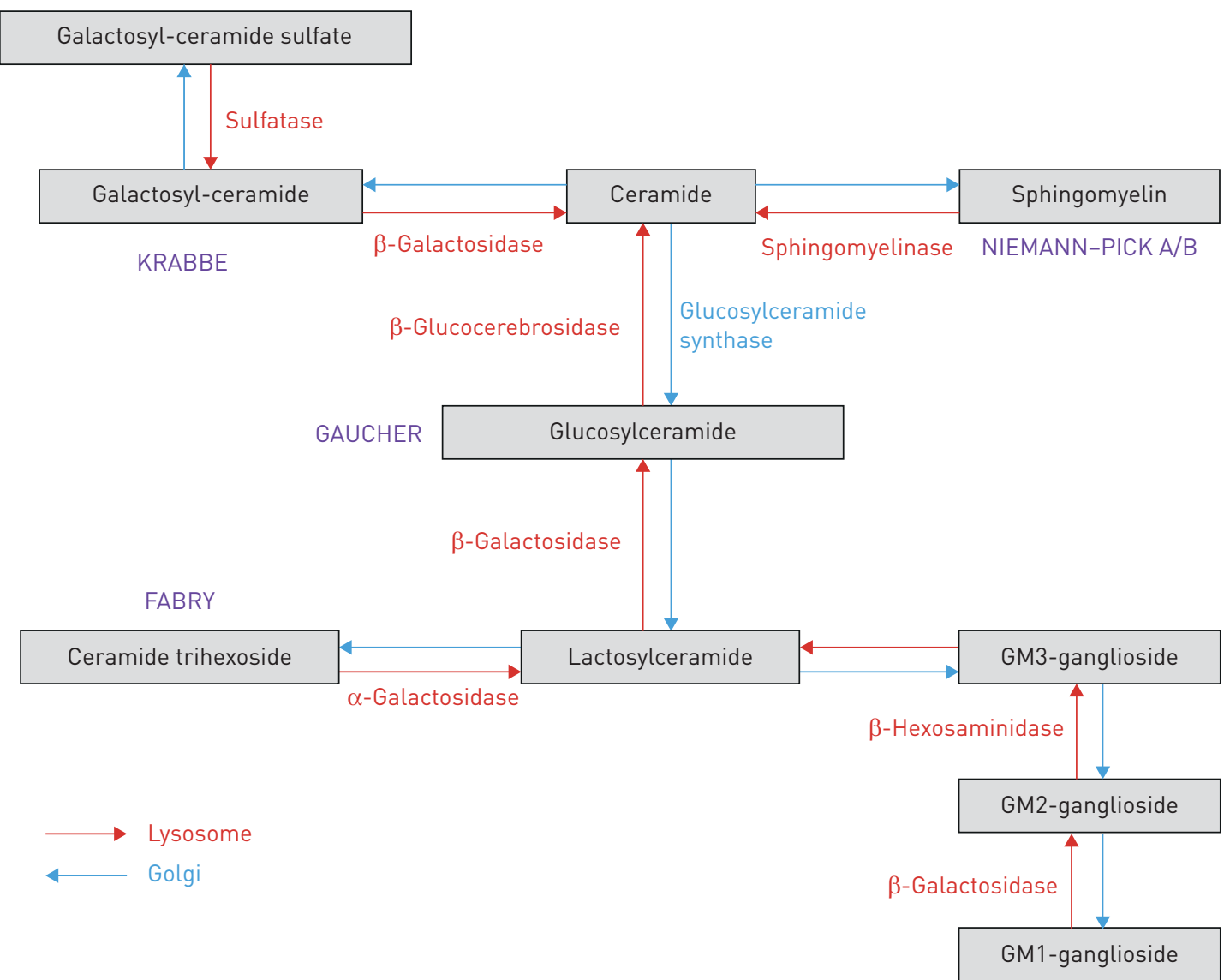

TAY-SACHS SANDHOFF

FIGURE 2 Metabolism of sphingolipids. Sphingolipids diffuse and switch between the membranes of lysosomes and the Golgi. Diseases corresponding to the accumulation of the adjacent substrate are reported in purple.

coagulation and specific inherited deficiencies in coagulation factors such as fibrinogen, and factors II, VII, VIII, X, XI or XII [13].

Despite ERT, 70-100\% of patients with GD1 show clinical or radiographic evidence of bone disease, which varies from asymptomatic osteopenia to focal lytic or sclerotic lesions and osteonecrosis [14]. Two-thirds of patients with GD report bone pain, predominantly in the pelvis and lower limb. Pain varies in severity, can be
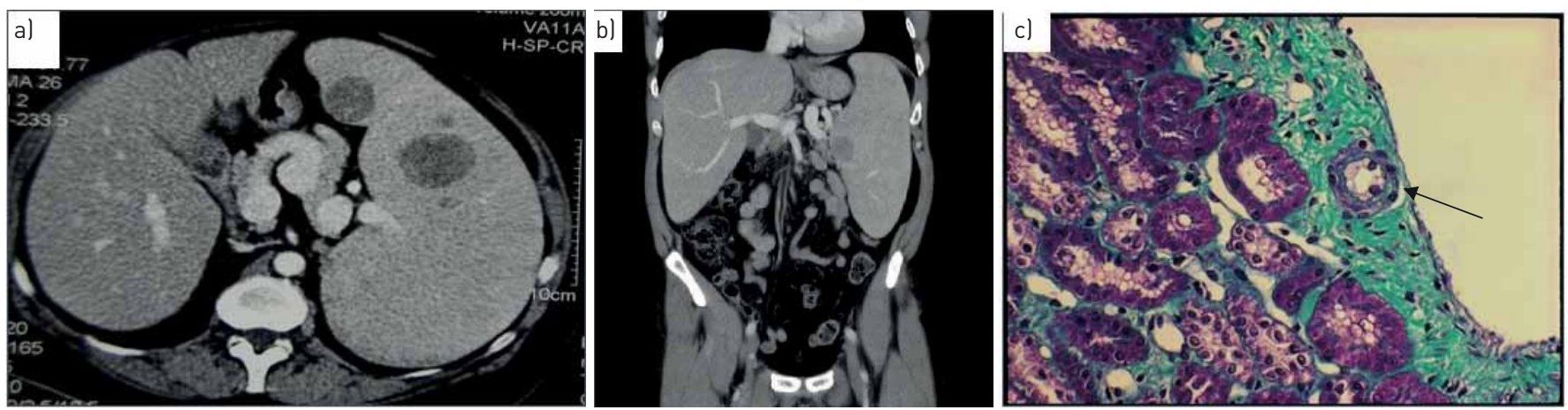

FIGURE 3 Characteristic manifestations of lysosomal storage disorders. a) Gaucher disease: computed tomography scan shows hepatosplenomegaly with focal lesion of "gaucheroma" (courtesy of N. Belmatoug, Beaujon hospital, Clichy, France). b) Acid sphingomyelinase deficiency: computed tomography scan shows hepatosplenomegaly. c) Fabry disease: kidney biopsy shows globotriaosylceramide deposition in glomerular, endothelial (arrow), mesangial, and interstitial cells and in podocytes (courtesy of L.H. Noel, Necker hospital, Paris, France). 
acute or chronic and is not always associated with radiological findings. One-third of patients with GD report bone crises (acute skeletal pain, fever and leukocytosis), with periosteal reaction [14, 15]. Patients with GD may present osteopenia/osteoporosis associated with risk of bone fracture, although the exact risk is incompletely evaluated by bone densitometry examination. Osteonecrosis of the femoral head, proximal humerus and vertebral bodies is frequent (34\%) and can result in fracture and joint collapse. Osteosclerosis may be observed after bone infarction [14]. Infiltration of bone marrow by Gaucher cells may cause ischaemia and pain. At a later stage of bone marrow infiltration, the risk of fracture and osteonecrosis is increased.

By definition, patients with GD1 do not present central nervous system disease, but neurological complications (spinal cord or nerve root compression) may occur secondary to bone disease, such as vertebral compression or bone fracture [16]. About 10\% of patients with GD present peripheral neuropathy [17]. Patients with GD1 are at high risk of Parkinson's disease [18]. Polyclonal hypergammaglobulinemia is frequent (25-91\% of cases) and monoclonal gammopathy is possible (1-35\% of cases). Indeed the risk of multiple myeloma is 6.7 in GD [19].

Chitotriosidase, CCL18 and glucosylsphingosine are three biomarkers whose levels are usually increased in GD and are sometimes used to monitor ERT. Ferritinaemia is increased in most patients with GD (>85\%), but iron, transferrin saturation and soluble transferrin receptor levels remain normal. Angiotensin-converting enzyme levels are greatly increased [20].

\section{Pulmonary manifestations}

Lung involvement is the result of infiltration of either alveoli, interstitium, bronchi or pulmonary vasculature by Gaucher's cells. Few cases of lung involvement of GD have been specifically reported. In a series of 411 patients with GD, only four adults and four children had respiratory symptoms and eventually showed ILD [21]. However, in a series of 150 consecutive patients with GD, five patients aged 11-55 years showed ILD on chest radiographs [22]. Patients with ILD showed a restrictive pattern on pulmonary function tests, with forced vital capacity (FVC) $29-76 \%$ predicted and a reduced diffusion capacity for carbon monoxide $\left(D_{\mathrm{LCO}}\right)$ of $38-61 \%$ pred [22].

In a series of 95 patients with GD with mean age 29 years, 68\% had some pulmonary function abnormalities [23]. The most common were reduced functional residual capacity (45\% of patients), reduced carbon monoxide transfer coefficient (42\% of patients) and reduced total lung capacity (about $25 \%$ of patients). Ten of the 81 (12.3\%) patients with available chest radiographs had ILD [23]. The relationship between ILD and pulmonary function is not reported because patients with GD may present restrictive syndrome secondary to hepatosplenomegaly and spinal deformities.

In a recent prospective series of 13 patients with GD (median age 15 year, range 1-50), two of 10 patients with available computed tomography (CT) scans had ILD and two additional patients had evidence of ILD on chest radiographs but without available CT scans [24].

Associations of genotype and phenotype in GD are imperfect and discordance in phenotype has been reported even among monozygotic twins [24]. However, ILD might be more frequent in patients with L444P homozygous mutations [24]. Ground-glass opacities that may be superimposed with interlobular thickening are the most common CT abnormalities [25] (figure 4).

When performed, bronchoalveolar lavage fluid analysis shows lipid-laden macrophages. When performed, lung biopsy shows foamy histiocytes in alveolar spaces, interstitial tissue and subendothelial locations [22]. Interstitial fibrosis and lymphocyte infiltrates may be present. Histological signs of pulmonary arterial hypertension may be evidenced: plexogenic arteriopathy, intimal fibrosis and medial hypertrophy, particularly at the time of lung transplantation [26, 27]. In addition to showing pulmonary hypertension and ILD, patients may present signs of chronic aspiration [28].

Pulmonary vascular diseases (figure 4) may be at the forefront in patients with GD with pulmonary arterial hypertension and hepatopulmonary syndrome, a well-documented risk factor in individual patients with liver disease, although pulmonary hypertension may also occur without liver disease [29]. Infections are probably not the only complication after splenectomy in GD. A specific risk of hepatopulmonary syndrome and pulmonary hypertension may exist after splenectomy in patients with GD [30, 31].

\section{Diagnosis}

The diagnosis of GD must be confirmed by glucocerebrosidase activity <15\% of the normal value [32] Bone marrow aspiration is not required for the diagnosis and should not routinely be performed in GD, 

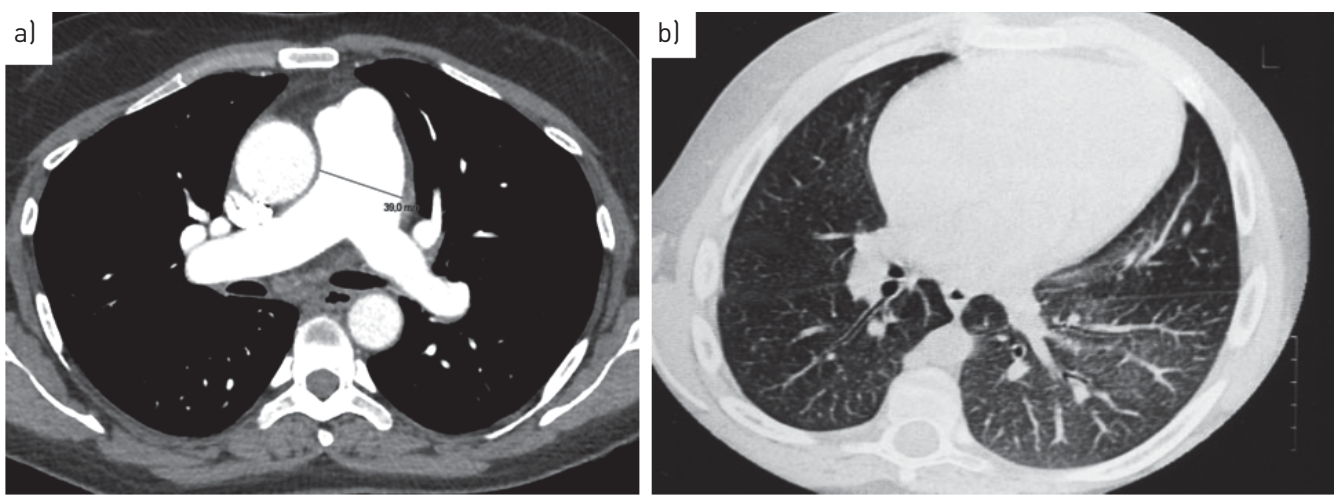

FIGURE 4 Lung computed tomography scan in two patients with Gaucher disease showing a) slightly increased pulmonary artery diameter suggestive of pulmonary hypertension (courtesy of N. Belmatoug, Beaujon hospital, Clichy, France), b) mild interstitial lung disease (courtesy of Generoso Andria, Federico II University, Naples, Italy; reproduced from [24] with permission).

although it is frequently performed in patients with thrombocytopenia and/or splenomegaly. Bone marrow aspiration shows Gaucher cells are sometimes difficult to distinguish from "pseudo-Gaucher" cells that are observed in some blood disorders or infectious diseases, such as myeloma with histiocytic accumulation of immunoglobulin crystals.

Glucocerebrosidase is encoded by the gene GBA1 [33]. More than 400 mutations have been described. The c.1226A>G mutation allele excludes risk of neurological involvement (GD2 or GD3) but does not predict the severity of bone and visceral involvement. Patients homozygous for the N370S mutation can remain asymptomatic, whereas homozygous L444P mutation carriers are at high risk of neurological manifestations (GD2 or GD3). Homozygote carriers of the c.1342G $>$ C (D409H) mutation present characteristic heart valve damage. Homozygous carriers of null mutations do not survive beyond the perinatal period.

\section{Treatment}

Enzyme replacement therapy

GD was the first LSD with a dedicated therapy available since 1991. The natural history of GD has been greatly modified by the development of three ERT agents (imiglucerase, velaglucerase, taliglucerase) because juvenile onset of dyspnoea leading to pulmonary failure and death were reported before the era of ERT [34, 35].

Regular intravenous infusions of the recombinant enzymes have been found safe and effective in reversing haematological and visceral (liver or spleen) involvement [36]. For instance, a 14-year-old patient showed a reversal of hepatopulmonary syndrome and liver disease with imiglucerase as assessed by pulse oximetry improved from $72 \%$ to $95 \%$ on room air [37]. However, rare reported cases have not shown alleviation of ILD with ERT [21, 38].

At least four patients have received lung transplantation for GD, although two did not present ILD but rather pulmonary hypertension. A child with severe ILD underwent lung transplantation at age 10 and did not present any signs 3 years later [39]. An adult patient with ILD associated with severe pulmonary hypertension underwent lung transplantation at age 49 [26]. He had to undergo kidney transplantation 21 months after lung transplantation because of end-stage renal insufficiency but was doing well 6 years after lung transplantation [26].

\section{Substrate inhibitor therapy}

Eligustat, orally available, showed long-term benefit, in keeping with established therapeutic goals for GD1 [40].

Nonspecific therapy

Physiotherapy, nutrition and vaccinations should be closely monitored and bronchoscopy may be required for removing bronchial casts [25]. Opportunistic pulmonary infections should be monitored and specifically treated because patients with GD without ERT may be at increased risk of aspergillosis or mycobacterial infection [41]. 
Avoiding splenectomy is crucial because the procedure is associated with risk of pulmonary hypertension and worse survival in GD [31, 42]. Indeed, pulmonary hypertension may develop in a few patients with GD after splenectomy despite specific ERT [42].

\section{Niemann-Pick disease}

Niemann-Pick disease, renamed ASMD type A, B or AB, is an autosomal recessive disease secondary to ASMD, responsible for the abnormal accumulation of lipids, including sphingomyelin and cholesterol (figure 2). It is a rare disease without a male-female predominance and with an estimated incidence of 0.4 to 1 in 100000 newborns [43]. The pathophysiology of type C is different, with central nervous system involvement, and is out of the scope of this review.

ASMD is caused by mutations in the sphingomyelin phosphodiesterase 1 (SMPD1) gene. The estimated prevalence is 1 in $50000-250000[7,44]$.

\section{Extrapulmonary manifestations}

The more severe clinical presentation is a neurovisceral infantile form in type A, with severe neurological involvement in childhood. A chronic visceral form presenting hepatosplenomegaly and pulmonary involvement is the most frequent type B form and may be also encountered in adults [45]. Indeed ASMD-B should be suspected in individuals with hepatosplenomegaly, ILD, hyperlipidaemia or thrombocytopenia (figures 5 and 6).

Hypersplenism causes secondary thrombocytopenia and is associated with spleen infarction, as revealed by acute abdominal pain [46]. Liver enlargement is common. Some individuals have slightly elevated liver enzyme activity and some have histological abnormalities ranging from hepatic fibrosis to established cirrhosis [47]; rare cases of liver failure requiring liver transplantation have been reported [48].

Almost one-third of patients with AMSD-B exhibit neurological signs [49]. The most frequent sign is nonprogressive hypotonia and/or hyporeflexia. Severe and progressive manifestations are rare and include cerebellar signs (nystagmus, extrapyramidal syndrome), intellectual disability, psychiatric disorders, peripheral neuropathy and retinal abnormalities, with onset between the ages of 2 and 7 years. Up to
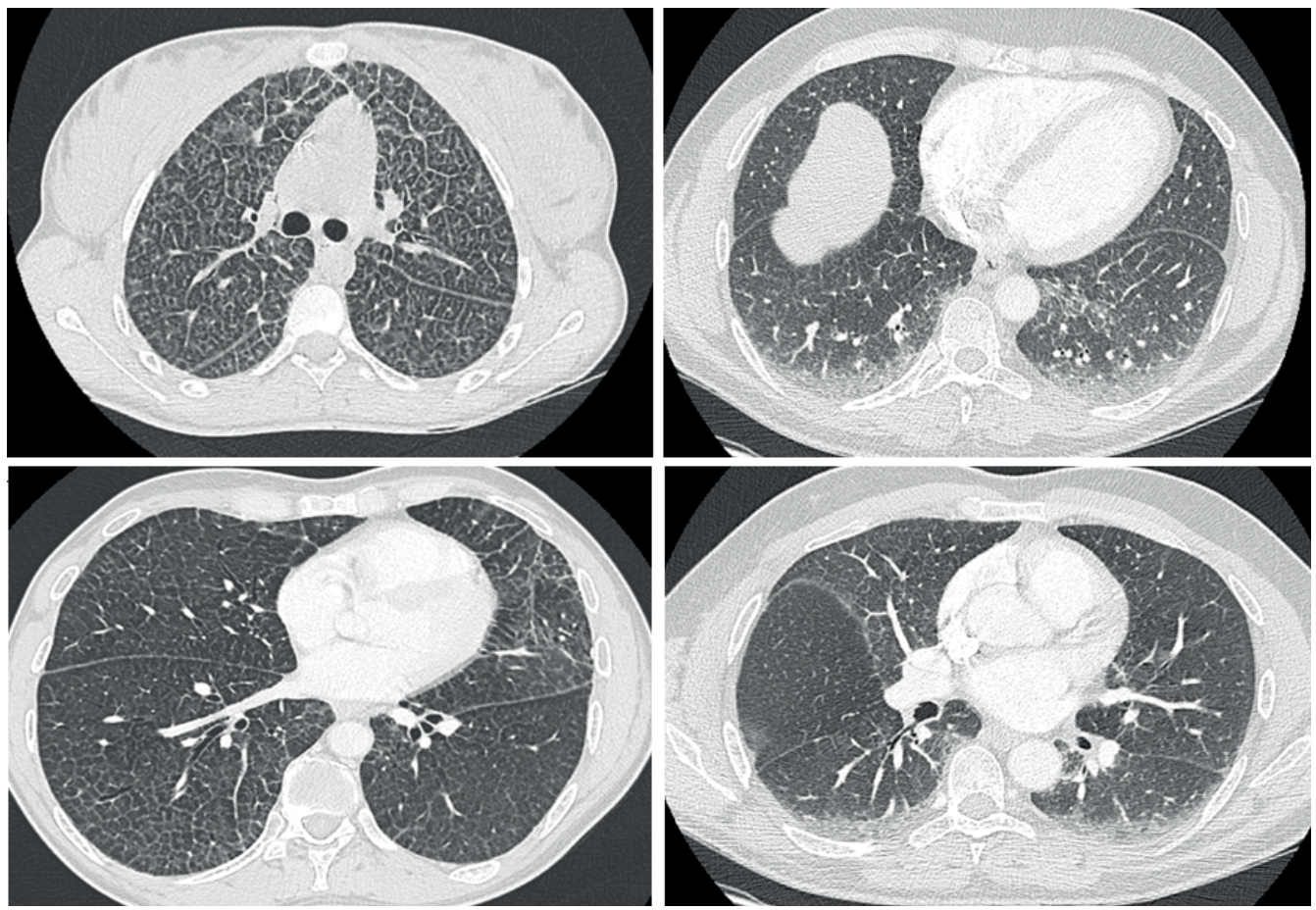

FIGURE 5 Representative lung computed tomography scan of acid sphingomyelinase deficiency. Coronal computed tomography images are from the same patient and show interstitial lung disease (parenchymal window). 


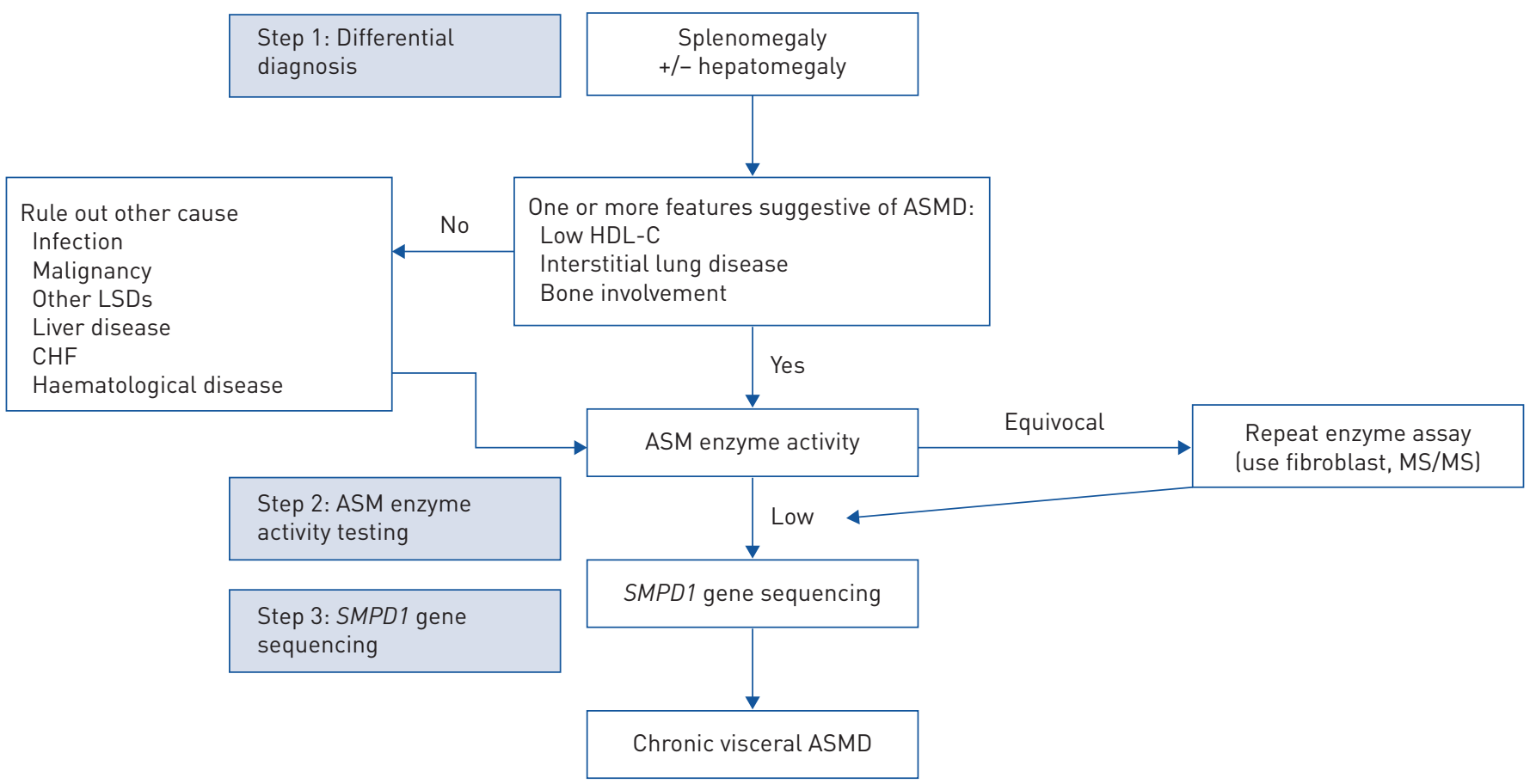

FIGURE 6 Diagnostic algorithm for acid sphingomyelinase deficiency (ASMD) presenting after childhood (adapted from [112]). ASM: acid sphingomyelinase; CHF: congestive heart failure; HDL-C: high-density lipoprotein-cholesterol; LSD: lysosomal storage disorders; MS/MS: tandem mass spectrometry.

one-third of patients have a macular halo or cherry-red macula without any loss of vision or sign of neurological disease [50].

Limited growth and abnormal bone maturation are common in children and may result in substantially short stature in adulthood. In one study, the mean Z-scores for height and weight were -1.24 (29th centile) and -0.75 (34th centile) and skeletal age in children under age 18 years was delayed by a mean of 2.5 years [51]. Short stature and low weight are associated with organomegaly and delayed bone age [51]. More than $90 \%$ of ASMD-B adults have osteopenia or osteoporosis at one or more sites. Overall, 58\% of adults report at least one fracture at a mean age of 33 years [52].

Low serum level of high-density lipoprotein-cholesterol is a constant feature [50]. In most individuals, low serum level of high-density lipoprotein-cholesterol is associated with hypertriglyceridaemia and elevated serum level of low-density lipoprotein-cholesterol. Early coronary artery disease may be related to the dyslipidaemia. Enlargement and calcifications in the adrenal glands may be seen [53]. ASMD-B women can have normal pregnancies and childbirth, without fetal growth issues despite hepatosplenomegaly [54].

\section{Pulmonary manifestations}

Pulmonary involvement, mainly ILD, occurs in all three types of ASMD but most frequently in type B. ILD may be diagnosed in newborns to adults in their late 40s, may precede ASMD diagnosis or may develop during follow-up [55, 56]. Up to $42 \%$ of patients report shortness of breath at ASMD diagnosis [46].

The clinical ILD presentation varies from asymptomatic involvement to respiratory failure with no association with organomegaly [57]; however, the accumulation of Niemann-Pick cells in the alveolar septa and bronchial walls potentially leads to progressive respiratory insufficiency [55]. When present, respiratory symptoms are generally mild, with recurrent cough, moderate exertional dyspnoea and recurrent respiratory infections. However, both rapidly fatal lung disease and progressive pulmonary disease leading to lung failure have been reported [55].

Almost 90\% of patients with ASMD-B exhibit ILD on CT scan [58]. The most frequent anomalies are ground-glass opacities (up to 100\%), interlobular septal thickening (up to 100\%) and intralobular lines 
(90-100\%) as well as superimposed ground glass on interlobular septal thickening (crazy paving pattern 40\%) [58, 59] (figure 5). Cysts, centrilobular nodular opacities, peribronchovascular thickening, segmental atelectasis, bronchiectasis and emphysema are rare [58, 59]. Pleural effusion and thoracic lymphadenopathy have not been described. Ground-glass opacities are usually focal (75\%) and may predominate in the upper lung zones, whereas reticulation usually predominates in the lower zone [60, 61]. Calcified pulmonary nodules can also be seen. The pulmonary involvement is bilateral without lateral predominance [59].

Bronchoalveolar lavage fluid analysis usually confirms the lung involvement, showing increased cell numbers (median $1.5 \times 10^{6} \mathrm{~mL}^{-1}$ ) and large multivacuolated histiocytes containing granules stained deep blue with May-Grunwald-Giemsa (MGG) stain (Niemann-Pick cells or "sea blue" histiocytes), accounting for more than $90 \%$ of the alveolar macrophages [55] (figure 7). Microbiology results are usually negative.

A lung biopsy is not required for diagnosis but, when performed, shows the presence of numerous finely vacuolated foamy macrophages located within the alveoli and to a lesser extent thickening the alveolar walls, supporting an endogenous lipid pneumonia [55, 62]. AMSD-B biopsy displays vacuolation of bronchial ciliated epithelium, without vacuolation of type 2 pneumocytes. Mild inflammation and interstitial fibrosis may be observed, with only minimal loss of architecture [55, 58].

There is a poor correlation between the extent of radiological abnormalities and pulmonary function test changes [58]. In a cohort of 55 patients with ASMD-B, half presented a restrictive pattern on pulmonary function testing (mean FVC $82 \%$ pred). Almost $75 \%$ of patients with ASMD-B present impaired $D_{\text {LCO }}$ (mean $D_{\text {LCO }} 60 \%$ pred) $[9,46,58]$. In addition, mean values for FVC and $D_{\text {LCO }}$ are lower in patients who are $<18$ than $>18$ years old [46]. Hypoxaemia is frequent and may be observed in up to $85 \%$ of patients [55].

A retrospective study of 29 paediatric and adult patients with ASMD-B with a mean follow-up of 4.3 years documented slow progression of pulmonary disease. The mean decline per year of forced expiratory volume in $1 \mathrm{~s}\left(\mathrm{FEV}_{1}\right), \mathrm{FVC}$ and $D_{\mathrm{LCO}}$ was $-1.6 \%,-0.1 \%$ and $-0.4 \%$ pred, respectively [46]. In another series of 10 paediatric patients with ASMD-B, all showed respiratory symptoms and three required long-term oxygen therapy [55].

Age of death of patients with ASMD-B ranges from 2 to 72 years old, with a mean age at death of 25 years $[48,63]$.

Overall, respiratory disease represents $\sim 25 \%$ of the causes of death in patients with ASMD-B [48, 63]. Other causes include liver disease $(\sim 25 \%)$ and other rare causes of death (cancer, multiple organ failure, cardiac event, bleeding and severe progressive neurodegeneration (ASMD-A); 5-10\% each) [63]. In patients with a diagnosis after age 18, death from respiratory issues (44.4\%) is the leading cause of death [63].

Of the patients who die from respiratory disease, half die during childhood [63]. The median age at death is 18 years. Most patients die from ILD (82\%), which may be associated or not with infectious pneumonia (30\%) or pulmonary embolism (4\%) [63].
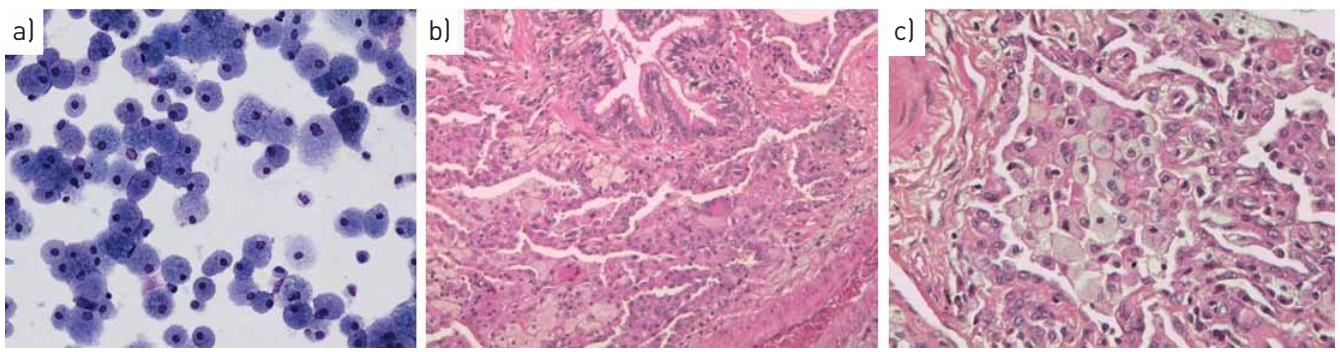

FIGURE 7 a) Bronchoalveolar lavage and b and c) transbronchial biopsy samples from a patient with acid sphingomyelinase deficiency: large multivacuolated histiocytes containing granules stained deep blue with May-Grunwald-Giemsa stain. 


\section{Diagnosis}

The diagnosis of ASMD is established by detection of: 1) low residual enzyme activity in leukocytes; and 2) SMPD1 gene mutation analysis showing biallelic pathogenic variants [64] (figure 6). Because of the bone marrow involvement, bone marrow examination may be performed to identify lipid-laden macrophages, although bone marrow examination is not necessary for diagnosis and should not be performed unless for specific clinical indications of ongoing therapies.

Patients homozygous for the p.Arg610del mutation have mild disease: normal height and weight, less hepatosplenomegaly and bone age delay [65]. Some other mutation alleles such as p.Leu139Pro, p.Ala198Pro and p.Arg476Trp result in less severe forms of ASMD-B [54]. p.Gln294Lys is associated with intermediate phenotypes with later-onset neuronopathic disease and seems to be more frequent in patients of Czech and Slovak origin [66]. p.His423Tyr and p.Lys578Asn are mostly found in Saudi Arabians and lead to an early-onset severe form of the disease [67]. Lipid abnormalities occur with all genotypes, including patients with p.Arg610del homozygous mutations [54].

\section{Treatment}

Management of ASMD-B requires a multidisciplinary approach. Splenectomy is not recommended because it may be associated with exacerbation of the pulmonary disease [46]. However, splenectomy may be required with extensive spleen necrosis [68]. Patients with clinically significant cytopenia may require multiple blood transfusions. Statins are offered for treating ASMD-associated hypercholesterolaemia. Patients with progressive pulmonary disease may require chronic oxygen therapy. Vaccination against influenza and Streptococcus pneumoniae should be considered.

Until recently, no specific therapies were available for ASMD-B, though anecdotal cases of whole lung lavage or lung or bone marrow transplantation have been reported. Several cases of therapeutic lung lavage have been reported in ASMD-B and associated with temporary clinical improvement [62, 69-71]. Endoscopic treatment of bronchial casts may be urgently required [62]. However, several patients eventually died of respiratory failure without knowing the impact of therapeutic lavage [69, 70].

At least three cases of lung transplantation in ASMD-B have been reported [72-74]. One patient died at day 29 post-transplantation, one was discharged at day 80 and the last one was still alive 35 months after lung transplantation [72, 73]. However, lung transplantation involves two important issues: 1) the disease may reappear; and 2) debulking of ceramide after cleavage of the sphingomyelin substrate by transplanted lung cells may cause a pro-inflammatory cascade, by releasing ceramide likewise in the ERT (see below) [75].

\section{Enzyme replacement therapy}

Olipudase alfa, a recombinant human acid sphingomyelinase, has shown promising results as an ERT. A phase I clinical trial included 11 patients with ASMD-B [76]. Patients were monitored after intravenous infusion of $0.03-1.0 \mathrm{mg} \cdot \mathrm{kg}^{-1}$ olipudase alfa. Blood ceramide levels increased up to 5-fold dose- and time-dependently, beginning 2-6h after infusion, peaking between 24 and $48 \mathrm{~h}$ and returning to pre-infusion levels by day 14 . No adverse events were reported at doses of 0.03 and $0.1 \mathrm{mg} \cdot \mathrm{kg}^{-1}$. For doses $\geqslant 0.3 \mathrm{mg} \cdot \mathrm{kg}^{-1}$, no adverse events occurred during the infusions, but four of the five patients experienced fever, pain, nausea or vomiting $12 \mathrm{~h}$ after the infusion. C-reactive protein, ferritin and fibrinogen levels and neutrophil count increased, with a peak between 48 and $72 \mathrm{~h}$ after infusion. Most adverse events did not require intervention and resolved within 1 or 2 days. This study identified $0.6 \mathrm{mg} \cdot \mathrm{kg}^{-1}$ as the maximum starting dose of olipudase alfa and supported a dose-escalation strategy to gradually clear accumulated sphingomyelin.

A phase II/III trial of adults with ASMD has finished. The results are only available in a press release at the moment (ASCEND study) [77]. This 52-week randomised controlled trial included 36 adult patients worldwide. Patients received up to $3 \mathrm{mg} \cdot \mathrm{kg}^{-1}$ of olipudase alfa every other week. At 52 weeks, the absolute increase in mean $D_{\mathrm{LCO}}$ (primary end-point) was $22 \%$ in the treatment group versus $3 \%$ in the placebo group ( $\mathrm{p}=0.0004)$. The spleen volume decreased by $39.5 \%$ in the treatment group but increased $0.5 \%$ in the placebo group $(\mathrm{p}<0.0001)$. The treatment was well tolerated.

An open study of children (ASCEND-Peds) included 20 patients from newborns to age 18 years to receive up to $3 \mathrm{mg} \cdot \mathrm{kg}^{-1}$ of olipudase alfa. All patients reported at least one adverse event: fever, cough, rhinitis, diarrhoea, nausea. One patient had a severe anaphylactic reaction related to olipudase alfa. Five other serious adverse events related to the treatment were reported: asymptomatic transitory elevation of alanine aminotransferase activity $(n=2)$, anaphylactic reaction $(n=1)$, skin eruption $(n=1)$ and urticaria $(n=1)$. Mean 
increase in $D_{\text {LCO }}$ was $33 \%$ after 52 weeks (9 patients). Mean decrease in spleen volume was 49\% (range 23-61\%) [77].

Long-term effects of olipudase alfa are unknown, but the striking improvement in the two primary end-points, spleen volume and $D_{\mathrm{LCO}}$, after 1 year of treatment, suggests a major breakthrough for patients with ASMD-B. Olipudase alfa is not currently available except for patients included in clinical trials.

\section{Fabry disease}

FD is an X-linked lysosomal storage disorder caused by mutation of the $\alpha$-galactosidase gene $(G L A)$ causing deficiency of $\alpha$-galactosidase A activity [78] (figure 2). This enzymatic defect leads to the progressive accumulation of glycosphingolipids resulting in neurological, ocular, skin, renal and cardiac manifestations in classical FD [78]. Respiratory symptoms are most frequently related to COPD-like or cardiac involvement. Respiratory symptoms are frequent in FD, but ILD is rare.

FD is pan-ethnic and the reported annual incidence is 1 in 100000 [7]. The historical cohort of FD featured full-blown disease with a multisystemic disorder, but analysis of a more recent cohort suggested that the cardiologist diagnoses most FD, with prominent hypertrophic cardiomyopathy [79].

\section{Extrapulmonary manifestations}

Early signs involve small nerve fibres of the peripheral and autonomic nervous systems [80]. About 60-80\% of patients with FD report pain (burning and tingling), which is one of the earliest symptoms. Gastrointestinal involvement, related to autonomic nervous system involvement, is common: abdominal pain (particularly after eating), diarrhoea, nausea and vomiting, a cause of anorexia [81].

Skin manifestations include anhidrosis or hypohidrosis that can cause heat and exercise intolerance [82] as well as angiokeratoma. Histologically, the skin lesions are small superficial angiomas caused by cumulative damage of vascular endothelial cells of the skin with vessel dilatation in the dermis [83]. Ophthalmological manifestations include corneal changes (“cornea verticillate"), detectable by slit-lamp examination and retinal vessel tortuosity. Tinnitus may be an early symptom and hearing loss has been reported in children [84]. Almost all patients with FD present corneal opacities, which may be associated with tortuosity of the conjunctival and retinal vessels without impaired visual acuity [85]. However, lens opacities are also observed [85].

Renal lesions result from globotriaosylceramide deposition in the glomerular endothelial, mesangial, and interstitial cells and in podocytes [86] (figure 3). Renal manifestation begins with microalbuminuria and proteinuria in the second to third decade [86]. Once a critical number of nephrons have been damaged, renal function will progressively decline, with progression to end-stage renal failure between the fourth and fifth decade in untreated patients with FD [86]. Before 2001, renal failure was the main cause of death (42\%) for patients with FD [87].

Cardiac manifestations include ventricular hypertrophy, arrhythmia and ischaemia, reported in 40-60\% of patients with FD [88]. Early signs of cardiac involvement may appear during adolescence, with involvement of the sinus node and conduction system, and include shortened PR interval, arrhythmias, impaired heart rate variability and mild valvular insufficiency [89]. Cardiac hypertrophy is typically nonobstructive and impairs diastolic and systolic function [88]. Arrhythmias can lead to sudden death, and 15-20\% of patients with FD require a pacemaker and/or implantable cardioverter defibrillator [90]. Cardiac events have been the main cause of death since 2001 (34-62\%) [91].

In addition to neuropathic manifestations and autonomic dysfunction, patients with FD often present cerebrovascular complications in adulthood as a result of multifocal small-vessel involvement [92]. Cerebrovascular manifestations vary from mild headache to severe, although rare, dementia, ischaemic stroke being the most frequent manifestation [92]. The prevalence of stroke in FD is $6.9 \%$ in men and $4.3 \%$ in women, with a median age of 39 years at the first stroke, and stroke may be the first manifestation of the disease [93]. In addition, $80 \%$ of patients with FD show progressive auditory and vestibular loss [94].

\section{Pulmonary manifestations}

A retrospective study of 95 adults reported a mean $\mathrm{FEV}_{1}$ of $80-90 \%$ pred, mean FVC of $92-99 \%$ pred, and mean $D_{\text {LCO }}$ of $86 \%$ pred at a median age of 38 years [95]. Thirteen patients (14\%), most often smokers, had obstructive lung disease. The mean decline in $\mathrm{FEV}_{1}, \mathrm{FVC}$ and $D_{\mathrm{LCO}}$ was $-29 \mathrm{~mL} \cdot \mathrm{year}^{-1}$ (95\% CI -36 to $-22 \mathrm{~mL}),-20 \mathrm{~mL} \cdot$ year $^{-1}(95 \% \mathrm{CI}-29$ to $-11 \mathrm{~mL})$ and $-0.14 \% \mathrm{pred}^{-y_{e a r}{ }^{-1}}$ (95\% CI $-0.32 \%$ to $0.03 \%)$. Obstructive lung disease developed in 31 (32\%) patients. The risk of obstructive lung 

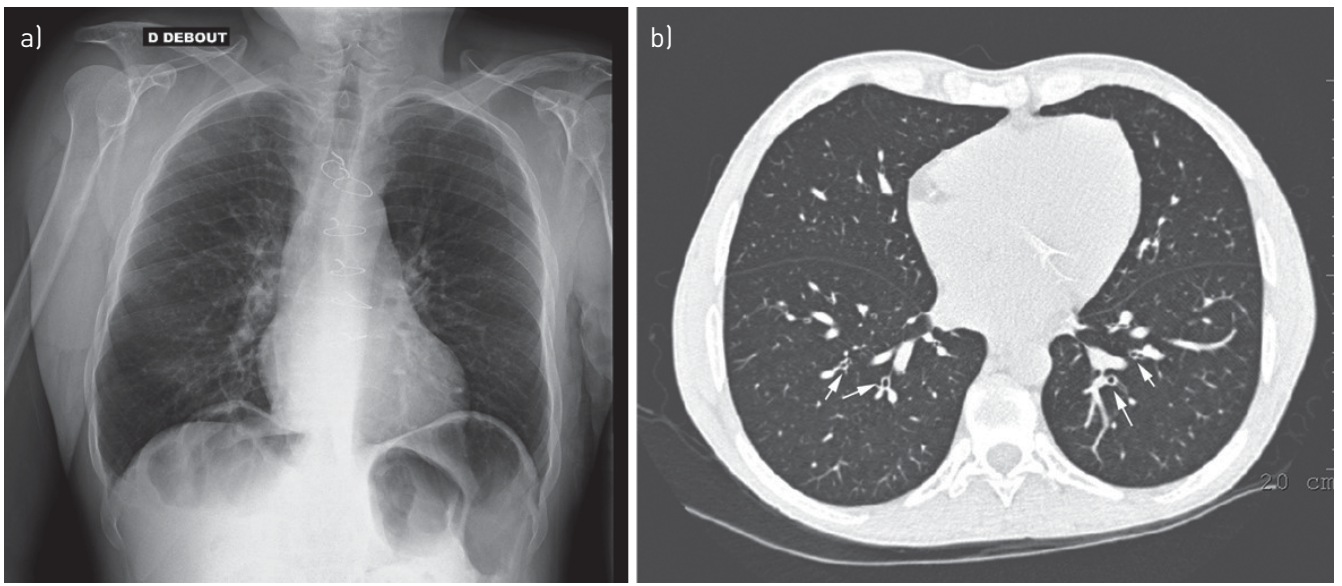

FIGURE 8 A 56-year-old patient with Fabry disease who underwent kidney and heart transplantation in 2006. a) Chest radiograph: colectasis and pulmonary distension. b) Computed tomography scan: bronchial thickening (arrows).

disease was increased in men and smokers. In a subset of 53 patients with available data before and after ERT, the annual changes in pulmonary function were not modified as compared with before therapy. The prevalence of ILD was not reported in these cohorts but does not appear to be relevant according to pulmonary function test results [95].

However, the prevalence of obstructive lung disease (32.3\%) seems increased in patients with FD and is usually diagnosed before age 40 as compared with the usual prevalence of $1-3.4 \%$ in the same age group [96, 97] (figure 8). In a cohort of 66 patients included in the Fabry Outcome Survey and with FEV 1 measurements, 14 of 31 (45.1\%) men and 9 of 35 (25.7\%) women had airway obstruction [96]. Pathophysiological mechanisms of airway obstruction may be related to glycosphingolipid accumulation in the bronchiolar smooth muscle cells leading to small airway disease [98]. Indeed, COPD-like symptoms are usually not beta-2 reversible in patients with FD [99].

Some radiological features of small airway disease, a mosaic attenuation pattern, might be mistaken for ILD, although authentic cases of patients with ILD and ground-glass pulmonary infiltrations on CT scan were reported $[98,100]$.

As far as we know, only one study evaluated systematic chest CT scans in patients with FD, although data are scarce. In a cohort of 17 patients, 2 had "pulmonary fibrosis", another had opacities potentially related to an infection and a fourth had pulmonary calcifications without additional data [101]. Impaired gas exchange and patchy ground-glass opacities on chest CT were reported in two case reports of two women [102, 103]. In one case, the pathological findings were reversible after ERT with agalsidase beta [103], whereas the other showed no response to treatment in terms of radiographic findings, although dynamic lung volume $\left(\mathrm{FEV}_{1}\right.$, FVC and $\mathrm{FEF}_{25-75 \%}$ (forced expiratory flow at 25-75\% of FVC)) improved and $D_{\text {LCO }}$ stabilised [102]. The authors of the latter report concluded that pulmonary interstitial fibrosis is progressive and does not respond to ERT if a certain "point of no return" has been exceeded [102]. Regardless, from the current literature, there is no clear-cut evidence for involvement of the lung interstitium in FD. Some of the reported changes are rather due to small airway disease because chest CT abnormalities and impaired $D_{\text {LCO }}$ are best compatible with bronchiolar dysfunction [104]. However, the filling of endothelial cells in the lung interstitium with sphingolipids may also impair $D_{\mathrm{LCO}}$. This hypothesis is supported by the improvement in $D_{\text {LCO }}$ after ERT with clearing of these deposits. In contrast, improvement of $D_{\text {LCO }}$ could, at least in part, be explained by improved cardiac function after ERT.

\section{Diagnosis}

Deficient activity of $\alpha$-galactosidase A is the reference laboratory method in men. Affected women may have enzyme activity within the normal range [105]. Therefore, all women should have their status determined by GLA genotyping. Normal LysoGb3 dosage has a high negative predictive value for excluding FD [106]. Of note, GLA features numerous variants of unknown significance, which should be interpreted in multidisciplinary discussions including geneticists and physicians $[107,108]$. 


\section{Management}

Supportive care is of particular importance in FD to address pain, gastrointestinal symptoms, stroke and hearing loss. Nonspecific treatment may include cardioverter defibrillator placement, aspirin and angiotensin-converting enzyme inhibitors.

ERT (agalsidase alfa, agalsidase beta) was introduced in 2001. $\alpha$-Galactosidase A treatment reduces pain and gastrointestinal symptoms (from 39-49\%), stabilises renal function and reduces left ventricular mass $[109,110]$. Several drugs such as chloroquine or amiodarone interfere with lysosome metabolism, and their prescription is contraindicated in addition to $\alpha$-galactosidase A. A new oral therapy has been available since 2016. Migalastat is an oral chaperone therapy targeting the misfolding protein and is appropriate for about one-third of patients according to the nature of the mutation [111].

\section{Conclusion}

Although GD, ASMD and FD all involve lysosomes, the pathophysiology of GD and ASMD is mostly related to macrophage dysfunction, whereas FD is more related to endothelial dysfunction, but all may induce organ fibrosis. Thus, early diagnosis is crucial to avoid irreversible damage. ERT exists (GD, FD) or is being investigated (ASMD, types $\mathrm{AB}$ and $\mathrm{B}$ ). In GD and in ASMD, a specialised evaluation of bronchoalveolar lavage fluid and lung biopsy can be informative, showing foamy cells or foamy macrophages/cells, respectively. In GD, ILD is rare. Splenectomy should be avoided and is associated with a specific risk of pulmonary hypertension. In ASMD, ILD is frequent and usually associated with spleen enlargement, low platelet cell count and low level of high-density lipoprotein-cholesterol. Pulmonary crackles are often missing or have a ventral localisation. Results of ERT are promising regarding preliminary results of olipudase in paediatric and adult ASMD including pulmonary end-points. The most frequent pulmonary manifestation in FD is COPD-like symptoms whatever the smoking habit.

Early diagnosis of these three LSDs is crucial to avoid irreversible organ damage. Early initiation of ERT can, at least in part, prevent organ failure. Lung involvement is part of the phenotype of LSDs. Long-term follow-up under ERT along with standard care will demonstrate or not whether lung involvement is reversible.

Provenance: Commissioned article, peer reviewed.

Previous articles in the Series: No. 1: Daccord C, Good J-M, Morren M-A, et al. Brit-Hogg-Dubé syndrome. Eur Respir Rev 2020; 29: 200042. No. 2: Hadchouel A, Drummond D, Abou Taam R, et al. Alveolar proteinosis of genetic origins. Eur Respir Rev 2020; 29: 200187. No. 3: Cazzato S, Omenetti A, Ravaglia C, et al. Lung involvement in monogenetic interferonopathies. Eur Respir Rev 2021; 30: 200001. No. 4: Yokoyama T, Gochuico BR. HermanskyPudlak syndrome pulmonary fibrosis: a rare inherited interstitial lung disease. Eur Respir Rev 2021; 30: 200193. No. 5: van Moorsel CHM, Van der Vis JJ, Grutters JC. Genetic disorders of the surfactant system: focus on adult disease. Eur Respir Rev 2021; 30: 200085. No. 6: Bode SFN, Rohr J, Müller Quernheim J, et al. Pulmonary granulomatosis of genetic origin. Eur Respir Rev 2021; 30: 200152.

Acknowledgements: The authors thank Claudia Helle (Sanofi-Genzyme, Paris, France) for providing figures 1 and 2.

Conflict of interest: R. Borie reports grants and personal fees from Roche and Boehringer-Ingelheim, and personal fees from Sanofi-Genzyme and Savara, outside the submitted work. B. Crestani reports grants and personal fees from Boehringer-Ingelheim, personal fees from Roche, Sanofi, Apellis and AstraZeneca and grants from Medimmune, outside the submitted work. A. Guyart has nothing to disclose. O. Lidove reports personal fees from Amicus, Genzyme/Sanofi and Takeda/Shire, outside the submitted work.

\section{References}

1 Ginzburg L, Kacher Y, Futerman AH. The pathogenesis of glycosphingolipid storage disorders. Semin Cell Dev Biol 2004; 15: 417-431.

2 Bowman SL, Bi-Karchin J, Le L, et al. The road to lysosome-related organelles: insights from HermanskyPudlak syndrome and other rare diseases. Traffic 2019; 20: 404-435.

3 Faverio P, Stainer A, De Giacomi F, et al. Molecular pathways and respiratory involvement in lysosomal storage diseases. Int J Mol Sci 2019; 20: 327.

4 Confalonieri M, Vitacca M, Scala R, et al. Is early detection of late-onset Pompe disease a pneumologist's affair? A lesson from an Italian screening study. Orphanet J Rare Dis 2019; 14: 62.

5 Peters $\mathrm{H}$, Ellaway C, Nicholls K, et al. Treatable lysosomal storage diseases in the advent of disease-specific therapy. Intern Med J 2020; 50: Suppl. 4, 5-27. 

comprehensive review of the literature. Hematology 2017; 22: 65-73. 249-254.

Stirnemann J, Vigan M, Hamroun D, et al. The French Gaucher's disease registry: clinical characteristics, complications and treatment of 562 patients. Orphanet J Rare Dis 2012; 7: 77.

Kaplan P, Andersson HC, Kacena KA, et al. The clinical and demographic characteristics of nonneuronopathic Gaucher disease in 887 children at diagnosis. Arch Pediatr Adolesc Med 2006; 160: 603-608.

10 Stone DL, Ginns El, Krasnewich D, et al. Life-threatening splenic hemorrhage in two patients with Gaucher disease. Am J Hematol 2000; 64: 140-142.

11 Ayto RM, Hughes DA, Jeevaratnam P, et al. Long-term outcomes of liver transplantation in type 1 Gaucher disease. Am J Transplant 2010; 10: 1934-1939.

12 Zimran A, Altarescu G, Rudensky B, et al. Survey of hematological aspects of Gaucher disease. Hematol Amst Neth 2005; 10: 151-156.

13 Deghady A, Marzouk I, El-Shayeb A, et al. Coagulation abnormalities in type 1 Gaucher disease in children. Pediatr Hematol Oncol 2006; 23: 411-417.

14 Wenstrup RJ, Roca-Espiau M, Weinreb NJ, et al. Skeletal aspects of Gaucher disease: a review. Br J Radiol 2002; 75: Suppl. 1, A2-A12.

15 Pastores GM, Patel MJ, Firooznia H. Bone and joint complications related to Gaucher disease. Curr Rheumatol Rep 2000; 2: 175-180.

16 Pastores GM, Barnett NL, Bathan P, et al. A neurological symptom survey of patients with type I Gaucher disease. J Inherit Metab Dis 2003; 26: 641-645.

17 Biegstraaten M, Mengel E, Maródi L, et al. Peripheral neuropathy in adult type 1 Gaucher disease: a 2-year prospective observational study. Brain J Neurol 2010; 133: 2909-2919.

18 Di Rocco M, Di Fonzo A, Barbato A, et al. Parkinson's disease in Gaucher disease patients: what's changing in the counseling and management of patients and their relatives? Orphanet J Rare Dis 2020; 15: 262.

19 Nair S, Branagan AR, Liu J, et al. Clonal immunoglobulin against lysolipids in the origin of myeloma. $N$ Engl J Med 2016; 374: 555-561.

20 Danilov SM, Tikhomirova VE, Metzger R, et al. ACE phenotyping in Gaucher disease. Mol Genet Metab 2018; 123: 501-510. Goitein O. Lung involvement and enzyme replacement therapy in Gaucher's disease. QJM 2001; 94: 407-415. Miller A, Brown LK, Pastores GM, et al. Pulmonary involvement in type 1 Gaucher disease: functional and exercise findings in patients with and without clinical interstitial lung disease. Clin Genet 2003; 63: 368-376. Kerem E, Elstein D, Abrahamov A, et al. Pulmonary function abnormalities in type I Gaucher disease. Eur Respir J 1996; 9: 340-345.

Santamaria F, Parenti G, Guidi G, et al. Pulmonary manifestations of Gaucher disease. Am J Respir Crit Care Med 1998; 157: 985-989.

Gülhan B, Özçelik U, Gürakan F, et al. Different features of lung involvement in Niemann-Pick disease and Gaucher disease. Respir Med 2012; 106: 1278-1285. de Boer GM, van Dussen L, van den Toorn LM, et al. Lung transplantation in Gaucher disease: a learning lesson in trying to avoid both scylla and charybdis. Chest 2016; 149: e1-e5. den Bakker MA, Grünberg K, Boonstra A, et al. Pulmonary arterial hypertension with plexogenic arteriopathy in enzyme-substituted Gaucher disease. Histopathology 2012; 61: 324-326. Goobie GC, Sirrs SM, Yee J, et al. Lessons from lung transplantation: cause for redefining the pathophysiology of pulmonary hypertension in gaucher disease. Respir Med Case Rep 2019; 28: 100893. Mistry PK, Sirrs S, Chan A, et al. Pulmonary hypertension in type 1 Gaucher's disease: genetic and epigenetic determinants of phenotype and response to therapy. Mol Genet Metab 2002; 77: 91-98. Jaïs X, loos V, Jardim C, et al. Splenectomy and chronic thromboembolic pulmonary hypertension. Thorax 2005; 60: 1031-1034.

31 Lo SM, Liu J, Chen F, et al. Pulmonary vascular disease in Gaucher disease: clinical spectrum, determinants of phenotype and long-term outcomes of therapy. J Inherit Metab Dis 2011; 34: 643-650.

32 Stirnemann J, Belmatoug N, Camou F, et al. A review of Gaucher disease pathophysiology, clinical presentation and treatments. Int J Mol Sci 2017; 18: 441.

33 Grabowski GA, Zimran A, Ida H. Gaucher disease types 1 and 3: phenotypic characterization of large populations from the ICGG Gaucher Registry. Am J Hematol 2015; 90: Suppl. 1, S12-S18.

34 Hollack CEM, Goudsmith R, Ek M, et al. Individualised low-dose alglucerase therapy for type 1 Gaucher's disease. Lancet 1995; 345: 1474-1478.

35 Schneider EL, Epstein CJ, Kaback MJ, et al. Severe pulmonary involvement in adult Gaucher's disease. Report of three cases and review of the literature. Am J Med 1977; 63: 475-480. 
Ben Turkia H, Gonzalez DE, Barton NW, et al. Velaglucerase alfa enzyme replacement therapy compared with imiglucerase in patients with Gaucher disease. Am J Hematol 2013; 88: 179-184.

Beshlawy AE, Murugesan V, Mistry PK, et al. Reversal of life-threatening hepatopulmonary syndrome in Gaucher disease by imiglucerase enzyme replacement therapy. Mol Genet Metab Rep 2019; 20: 100490.

Tezuka Y, Fukuda M, Watanabe S, et al. Histological characterisation of visceral changes in a patient with type 2 Gaucher disease treated with enzyme replacement therapy. Blood Cells Mol Dis 2018; 68: 194-199.

Rao AR, Parakininkas D, Hintermeyer M, et al. Bilateral lung transplant in Gauchers type-1 disease. Pediatr Transplant 2005; 9: 239-243.

Mistry PK, Balwani M, Charrow J, et al. Real-world effectiveness of eliglustat in treatment-naïve and switch patients enrolled in the International Collaborative Gaucher Group Gaucher Registry. Am J Hematol 2020; 95: 1038-1046.

Machaczka M, Lorenz F, Kleinotiene G, et al. Recurrent pulmonary aspergillosis and mycobacterial infection in an unsplenectomized patient with type 1 Gaucher disease. Ups J Med Sci 2014; 119: 44-49.

Elstein D, Klutstein MW, Lahad A, et al. Echocardiographic assessment of pulmonary hypertension in Gaucher's disease. Lancet 1998; 351: 1544-1546.

von Ranke FM, Pereira Freitas HM, Mançano AD, et al. Pulmonary involvement in Niemann-Pick disease: a state-of-the-art review. Lung 2016; 194: 511-518.

Acuña M, Martínez P, Moraga C, et al. Epidemiological, clinical and biochemical characterization of the $p$. (Ala359Asp) SMPD1 variant causing Niemann-Pick disease type B. Eur J Hum Genet 2016; 24: 208-213.

Schuchman EH. The pathogenesis and treatment of acid sphingomyelinase-deficient Niemann-Pick disease. J Inherit Metab Dis 2007; 30: 654-663.

McGovern MM, Wasserstein MP, Giugliani R, et al. A prospective, cross-sectional survey study of the natural history of Niemann-Pick disease type B. Pediatrics 2008; 122: e341-e349.

Thurberg BL, Wasserstein MP, Schiano T, et al. Liver and skin histopathology in adults with acid sphingomyelinase deficiency (Niemann-Pick disease type B). Am J Surg Pathol 2012; 36: 1234-1246.

McGovern MM, Lippa N, Bagiella E, et al. Morbidity and mortality in type B Niemann-Pick disease. Genet Med 2013; 15: 618-623.

Wasserstein MP, Aron A, Brodie SE, et al. Acid sphingomyelinase deficiency: prevalence and characterization of an intermediate phenotype of Niemann-Pick disease. J Pediatr 2006; 149: 554-559.

McGovern MM, Wasserstein MP, Aron A, et al. Ocular manifestations of Niemann-Pick disease type B. Ophthalmology 2004; 111: 1424-1427.

Wasserstein MP, Larkin AE, Glass RB, et al. Growth restriction in children with type B Niemann-Pick disease. J Pediatr 2003; 142: 424-428.

Wasserstein M, Godbold J, McGovern MM. Skeletal manifestations in pediatric and adult patients with Niemann-Pick disease type B. J Inherit Metab Dis 2013; 36: 123-127.

Alexander WS. Niemann-Pick disease; report of a case showing calcification in the adrenal glands. N Z Med J 1946; 45: 43-45.

Wasserstein MP, Schuchman EH. Acid sphingomyelinase deficiency. In: Adam MP, Ardinger HH, Pagon RA, et al., eds. GeneReviews. Seattle, University of Washington, 1993. www.ncbi.nlm.nih.gov/books/NBK1370/

Guillemot N, Troadec C, de Villemeur TB, et al. Lung disease in Niemann-Pick disease. Pediatr Pulmonol 2007; 42: 1207-1214.

Capron T, Trigui Y, Gautier C, et al. Respiratory impairment in Niemann-Pick B disease: two case reports and review for the pulmonologist. Respir Med Res 2019; 76: 13-18.

Hollak CEM, de Sonnaville ESV, Cassiman D, et al. Acid sphingomyelinase (Asm) deficiency patients in The Netherlands and Belgium: disease spectrum and natural course in attenuated patients. Mol Genet Metab 2012; 107: 526-533.

Mendelson DS, Wasserstein MP, Desnick RJ, et al. Type B Niemann-Pick disease: findings at chest radiography, thin-section CT, and pulmonary function testing. Radiology 2006; 238: 339-345.

Freitas HMP, Mançano AD, Rodrigues RS, et al. Niemann-Pick disease type B: HRCT assessment of pulmonary involvement. J Bras Pneumol 2017; 43: 451-455.

Minai OA, Sullivan EJ, Stoller JK. Pulmonary involvement in Niemann-Pick disease: case report and literature review. Respir Med 2000; 94: 1241-1251.

Chung MJ, Lee KS, Franquet T, et al. Metabolic lung disease: imaging and histopathologic findings. Eur J Radiol 2005; 54: 233-245.

Nicholson AG, Florio R, Hansell DM, et al. Pulmonary involvement by Niemann-Pick disease. A report of six cases. Histopathology 2006; 48: 596-603.

3 Cassiman D, Packman S, Bembi B, et al. Cause of death in patients with chronic visceral and chronic neurovisceral acid sphingomyelinase deficiency (Niemann-Pick disease type B and B variant): literature review and report of new cases. Mol Genet Metab 2016; 118: 206-213.

van Diggelen OP, Voznyi $\mathrm{V}$, Keulemans JLM, et al. A new fluorimetric enzyme assay for the diagnosis of Niemann-Pick A/B, with specificity of natural sphingomyelinase substrate. J Inherit Metab Dis 2005; 28: 733-741. 
Wasserstein MP, Desnick RJ, Schuchman EH, et al. The natural history of type B Niemann-Pick disease: results from a 10-year longitudinal study. Pediatrics 2004; 114: e672-e677.

Pavlů-Pereira $\mathrm{H}$, Asfaw B, Poupctová $\mathrm{H}$, et al. Acid sphingomyelinase deficiency. Phenotype variability with prevalence of intermediate phenotype in a series of twenty-five Czech and Slovak patients. A multi-approach study. J Inherit Metab Dis 2005; 28: 203-227.

Simonaro CM, Desnick RJ, McGovern MM, et al. The demographics and distribution of type B Niemann-Pick disease: novel mutations lead to new genotype/phenotype correlations. Am J Hum Genet 2002; 71: 1413-1419.

Lidove $\mathrm{O}$, Le Fèvre L, Goasguen N, et al. Déficit en sphingomyélinase acide et rupture splénique: splénectomie ou traitement conservateur? [Acid sphingomyelinase deficiency and spleen trauma: splenectomy or not splenectomy?] Rev Med Interne 2015; 36: 619-622.

Griese M, Brasch F, Aldana VR, et al. Respiratory disease in Niemann-Pick type C2 is caused by pulmonary alveolar proteinosis. Clin Genet 2010; 77: 119-130.

Uyan ZS, Karadağ B, Ersu R, et al. Early pulmonary involvement in Niemann-Pick type B disease: lung lavage is not useful. Pediatr Pulmonol 2005; 40: 169-172.

Nicholson AG, Wells AU, Hooper J, et al. Successful treatment of endogenous lipoid pneumonia due to Niemann-Pick Type B disease with whole-lung lavage. Am J Respir Crit Care Med 2002; 165: 128-131.

Mannem H, Kilbourne S, Weder M. Lung transplantation in a patient with Niemann-Pick disease. J Heart Lung Transplant 2019; 38: 100-101.

O'Neill RS, Belousova N, Malouf MA. Pulmonary type B Niemann-Pick disease successfully treated with lung transplantation. Case Rep Transplant 2019; 2019: 9431751.

Ding F, Mehta AC, Arrossi AV. Successful lung transplantation in a patient with Niemann-Pick disease. J Heart Lung Transplant 2019; 38: 582-583.

Lidove O, Mauhin W, London J. Acid sphingomyelinase deficiency (Niemann-Pick disease Type B) as an inflammatory disease. J Heart Lung Transplant 2019; 38: 583-584.

McGovern MM, Wasserstein MP, Kirmse B, et al. Novel first-dose adverse drug reactions during a phase I trial of olipudase alfa (recombinant human acid sphingomyelinase) in adults with Niemann-Pick disease type B (acid sphingomyelinase deficiency). Genet Med 2016; 18: 34-40.

Sanofi. Positive topline results demonstrated by olipudase alfa, first and only investigational therapy in late-stage development for acid sphingomyelinase deficiency. Press Release, January 30, 2020. www.sanofi. com/media-room/press-releases/2020/2020-01-30 07-00-00 1977201 Date last accessed: February 11, 2021. Date last updated: January 30, 2020.

Zarate YA, Hopkin RJ. Fabry's disease. Lancet 2008; 372: 1427-1435.

Mauhin W, Benveniste O, Amelin D, et al. Cornea verticillata and acroparesthesia efficiently discriminate clusters of severity in Fabry disease. PLoS One 2020; 15: e0233460.

Cable WJ, Kolodny EH, Adams RD. Fabry disease: impaired autonomic function. Neurology 1982; 32: 498-502.

Hoffmann B, Schwarz M, Mehta A, et al. Gastrointestinal symptoms in 342 patients with Fabry disease: prevalence and response to enzyme replacement therapy. Clin Gastroenterol Hepatol 2007; 5: 1447-1453.

Eng CM, Germain DP, Banikazemi M, et al. Fabry disease: guidelines for the evaluation and management of multi-organ system involvement. Genet Med 2006; 8: 539-548.

Orteu $\mathrm{CH}$, Jansen T, Lidove $\mathrm{O}$, et al. Fabry disease and the skin: data from FOS, the Fabry outcome survey. Br J Dermatol 2007; 157: 331-337.

Germain DP. Fabry disease. Orphanet J Rare Dis 2010; 5: 30.

Sodi A, Ioannidis AS, Mehta A, et al. Ocular manifestations of Fabry's disease: data from the Fabry Outcome Survey. Br J Ophthalmol 2007; 91: 210-214.

Ramaswami U, Najafian B, Schieppati A, et al. Assessment of renal pathology and dysfunction in children with Fabry disease. Clin J Am Soc Nephrol 2010; 5: 365-370.

Mehta A, Clarke JTR, Giugliani R, et al. Natural course of Fabry disease: changing pattern of causes of death in FOS - Fabry Outcome Survey. J Med Genet 2009; 46: 548-552.

Linhart A, Palecek T, Bultas J, et al. New insights in cardiac structural changes in patients with Fabry's disease. Am Heart J 2000; 139: 1101-1108.

Cabrera-Salazar MA, O'Rourke E, Charria-Ortiz G, et al. Radiological evidence of early cerebral microvascular disease in young children with Fabry disease. J Pediatr 2005; 147: 102-105.

Sené T, Lidove O, Sebbah J, et al. Cardiac device implantation in Fabry disease: a retrospective monocentric study. Medicine (Baltimore) 2016; 95: e4996.

Baig S, Edward NC, Kotecha D, et al. Ventricular arrhythmia and sudden cardiac death in Fabry disease: a systematic review of risk factors in clinical practice. Europace 2018; 20: f153-f161.

Fellgiebel A, Müller MJ, Ginsberg L. CNS manifestations of Fabry's disease. Lancet Neurol 2006; 5: 791-795.

Sims K, Politei J, Banikazemi M, et al. Stroke in Fabry disease frequently occurs before diagnosis and in the absence of other clinical events: natural history data from the Fabry Registry. Stroke 2009; 40: 788-794. 
Palla A, Hegemann S, Widmer U, et al. Vestibular and auditory deficits in Fabry disease and their response to enzyme replacement therapy. J Neurol 2007; 254: 1433-1442.

Franzen D, Haile SR, Kasper DC, et al. Pulmonary involvement in Fabry disease: effect of plasma globotriaosylsphingosine and time to initiation of enzyme replacement therapy. BMJ Open Respir Res 2018; 5: e000277.

Aubert JD, Barbey F. Pulmonary involvement in Fabry disease. In: Mehta A, Beck M, Sunder-Plassmann G, eds. Fabry Disease: Perspectives from 5 Years of FOS. Oxford, Oxford PharmaGenesis, 2006. www.ncbi.nlm. nih.gov/books/NBK11589/

Bridevaux P-O, Probst-Hensch NM, Schindler C, et al. Prevalence of airflow obstruction in smokers and never-smokers in Switzerland. Eur Respir J 2010; 36: 1259-1269.

Magage S, Lubanda J-C, Susa Z, et al. Natural history of the respiratory involvement in Anderson-Fabry disease. J Inherit Metab Dis 2007; 30: 790-799.

Franzen D, Krayenbuehl PA, Lidove 0 , et al. Pulmonary involvement in Fabry disease: overview and perspectives. Eur J Intern Med 2013; 24: 707-713.

Svensson CK, Feldt-Rasmussen U, Backer V. Fabry disease, respiratory symptoms, and airway limitation - a systematic review. Eur Clin Respir J 2015; 2: 1-2.

Koskenvuo JW, Kantola IM, Nuutila P, et al. Cardiopulmonary involvement in Fabry's disease. Acta Cardiol 2010; 65: 185-192.

Wang RY, Abe JT, Cohen AH, et al. Enzyme replacement therapy stabilizes obstructive pulmonary Fabry disease associated with respiratory globotriaosylceramide storage. J Inherit Metab Dis 2008; 31: Suppl. 2, S369-S374.

Kim W, Pyeritz RE, Bernhardt BA, et al. Pulmonary manifestations of Fabry disease and positive response to enzyme replacement therapy. Am J Med Genet A 2007; 143: 377-381.

Devakonda A, Raoof S, Sung A, et al. Bronchiolar disorders: a clinical-radiological diagnostic algorithm. Chest 2010; 137: 938-951.

Linthorst GE, Vedder AC, Aerts JMFG, et al. Screening for Fabry disease using whole blood spots fails to identify one-third of female carriers. Clin Chim Acta 2005; 353: 201-203.

Alharbi FJ, Baig S, Auray-Blais C, et al. Globotriaosylsphingosine (Lyso-Gb3) as a biomarker for cardiac variant (N215S) Fabry disease. J Inherit Metab Dis 2018; 41: 239-247.

van der Tol L, Smid BE, Poorthuis BJHM, et al. A systematic review on screening for Fabry disease: prevalence of individuals with genetic variants of unknown significance. J Med Genet 2014; 51: 1-9.

Borie R, Kannengiesser C, Gouya L, et al. Pilot experience of multidisciplinary team discussion dedicated to inherited pulmonary fibrosis. Orphanet J Rare Dis 2019; 14: 280.

West M, Nicholls K, Mehta A, et al. Agalsidase alfa and kidney dysfunction in Fabry disease. J Am Soc Nephrol 2009; 20: 1132-1139.

Baehner F, Kampmann C, Whybra C, et al. Enzyme replacement therapy in heterozygous females with Fabry disease: results of a phase IIIB study. J Inherit Metab Dis 2003; 26: 617-627.

1 Hughes DA, Nicholls K, Shankar SP, et al. Oral pharmacological chaperone migalastat compared with enzyme replacement therapy in Fabry disease: 18-month results from the randomised phase III ATTRACT study. J Med Genet 2017; 54: 288-296.

2 McGovern MM, Avetisyan R, Sanson B-J, et al. Disease manifestations and burden of illness in patients with acid sphingomyelinase deficiency (ASMD). Orphanet J Rare Dis 2017; 12: 41. 